\title{
Multi-cycle chemotherapy with the glycolipid-like polymeric micelles evade cancer stem cell enrichment in breast cancer therapy
}

\author{
Tingting Meng ${ }^{1}$, Jingwen Liu ${ }^{1}$, Lijuan Wen ${ }^{1}$, Ming Yuan ${ }^{1}$, Bolin Cheng ${ }^{1}$, Yingwen \\ $\mathrm{Hu}^{1}$, Yun Zhu ${ }^{1}$, Xuan Liu ${ }^{1}$, Hong Yuan ${ }^{1}$, Fuqiang Hu${ }^{1}$ \\ ${ }^{1}$ Institute of Pharmaceutics, College of Pharmaceutical Science, Zhejiang University, Hangzhou 310058, China \\ Correspondence to: Fuqiang Hu, email: hufq@zju.edu.cn \\ Keywords: multi-cycle chemotherapy, tumor repopulation, drug delivery, cancer stem cell, microenvironment
}

Received: April 05, 2016

Accepted: September 13, 2016

Published: September 21, 2016

\section{ABSTRACT}

Multi-cycle chemotherapy is commonly used in the clinic, while the phenomena of enrichment of cancer stem cells (CSCs) and enhanced multi-drug resistance (MDR) are commonly involved. This research was designed for evaluating this successive administration. Chitosan oligosaccharide-g-stearic acid (CSOSA) polymer was used as the drug delivery system (DDS) to perform tri-cycle chemotherapy on a new tumor model induced by mammosphere cells. In vitro, on CSCs enriched mammospheres model, the doxorubicin-loaded CSOSA (CSOSA/DOX) displayed an improved growth inhibition effect measured by acid phosphatase assay (APH). While in vivo, the CSOSA/DOX micelles blocked tumor progression and led to a marked decrease of CSCs proportion as well as MDR capacity. What's more, the CSOSA/DOX helped decay the microenvironment and attenuate systemic side effects. We concluded that the CSOSA polymer could be a potential DDS for long-term multi-cycle chemotherapy in antitumor research.

\section{INTRODUCTION}

Chemotherapeutic treatments are commonly used for cancer therapy. However, only specific subgroups of patients are likely to be cured. Dose escalation is not sufficient to result in an improved outcome because the chemotherapy doses are limited by bone marrow suppression and other toxicities [1,2]. The higher the drug dose is, the greater the cytotoxic effect is. An alternative method for increasing dose intensity would be to use multiple cycles' administration with reasonably short time intervals for recovery of normal tissue. Common used chemotherapies in clinical regimen are multi-cycle and repetitive. However, multiple stimulations of drugs would lead to the enrichment of cancer stem cells (CSCs) [3]. While, the CSCs can drive tumor growth and are responsible for further cancer progression, recurrence and metastasis [4]. Besides, their multi-drug resistance (MDR) capacity $[5,6]$ would significantly decrease the sensitivity of tumor cells to plenty chemicals and result in treatment failure. Taking strategies to reduce CSCs enrichment would be of vital help in cancer treatment.

Drug delivery system (DDS) has advantages in delivering therapeutic agents and passively concentrating agents within the tumor because of the enhanced permeability and retention (EPR) effect. Targeting strategies have been designed to remove CSCs in tumor $[7,8]$. In this research, the glycolipid-like stearic acid-gchitosan oligosaccharide (CSOSA) polymeric micelles which presented excellent drug accumulation in drug resistant cells $[9,10]$ were used as a DDS. We aimed to remove both bulk tumor cells and drug resistant CSCs in prevention of their mutual transformation. Besides, three cycles' repetitive chemotherapy with the drug loaded CSOSA micelles was designed to simulate the clinical regimen to detect its antitumor effect and to dig the changing rules of tumor pathology, CSCs proportion as well as MDR capability and the surrounding microenvironment when treated by free drugs and drug loaded DDS.

\section{RESULTS AND DISCUSSION}

\section{Preparation and characterization of CSOSA/ DOX}

The grafted polymer CSOSA self-assembled into micelles with hydrophilic shell and hydrophobic core 
in aqueous medium. The critical micelle concentration (CMC) value was $22.39 \mu \mathrm{g} / \mathrm{mL}$ calculated according to Figure 1A. Its chemical structure was confirmed by ${ }^{1} \mathrm{H}$ NMR (Supplementary Figure S1). After DOX was encapsulated, the particle size of micelles decreased from $53.8 \pm 3.2 \mathrm{~nm}$ to $34.6 \pm 12.7 \mathrm{~nm}$ because of the interaction between hydrophobic DOX and micelles' cores. Their size distribution was showed in Supplementary Figure S2. Zeta-potential values for CSOSA and CSOSA/DOX were $21.2 \pm 0.2 \mathrm{mV}$ and $22.0 \pm 0.7 \mathrm{mV}$, respectively. Photos taken by transmission electronic microscopy (TEM) (Figure 1B) showed the shape of the micelles with uniform size approximating what was measured above. DOX encapsulated in the micelles also showed a delayed release rate (Figure 1C) indicating its potential as a sustained release DDS.

\section{Enrichment of CSCs in mammospheres}

The serum-free suspension culture, which attempts to avoid differentiation stimulation by decreasing secretion of differentiation factors and cell adherence, is widely used to obtain CSCs [11]. As shown in Figure 2A, a single MCF-7 cell formed a spheroid structure and became more compact with a well-defined circular shape at the tenth day. We named this structure mammosphere as advised [12]. Following detachment, the cells could reform mammospheres again indicating their ability to self-renew.

To verify the stemness of mammospheres, flow cytometry (FCM) was performed to detect breast CSC surface maker CD $44^{+} / \mathrm{CD} 24^{-}$. The ratio of CD $44^{+} / \mathrm{CD} 24^{-}$ cells in mammospheres was as high as $36.51 \%$, while in MCF-7 cells it was only $0.73 \%$ (Figure 2B). OCT4, Nanog and SOX2 genes which were in charge of cell division and differentiation in stem cells [13] were also tested by RT-PCR and western-blot. The mRNA levels were all multiplied, of which SOX2 increased to almost five-fold; while three-fold, two-fold was for OCT4 and Nanog (Figure 2C). Similar to that, from a semiquantitative calculation of optical density, protein OCT4 was distinctive with three times higher. Meanwhile SOX2 and Nanog were both doubled (Figure 2D). Overall, they were inclined to possess the characters of stem cells.

Another important character of breast CSCs is drug resistance capacity associated with high levels of ABCG2 [14] which defend cells by decreasing cellular accumulation of cytotoxic agents. To observe the expression, mammospheres were frozen sectioned. And then enhanced ABCG2 expression was observed by a confocal laser scan microscopy (CLSM) through the fluorescence of ABCG2 antibody (Figure 2E). These three indexes confirmed that the cells in mammospheres had gained the characteristics of CSCs after serum free medium (SFM) conditioned cultivation. The structure of mammosphere was portrayed in Figure 2F.

\section{Deeper and more penetration of DOX delivered by CSOSA in mammospheres}

Cellular uptake and penetration experiment of doxorubicin hydrochloride (DOX $\cdot H C L)$ and micelleloaded DOX were performed on mammospheres. As a 3D structure, resembling tumorospheres, the mammpspheres can reflect nanoparticles penetration besides cellular uptake capability. After incubated with formulations for different time intervals, mammospheres were scanned layer by layer. The 3D images (Figure 3A) were reconstructed by piling up layers at different depths with the Imaris software. Fluorescence intensity in CSOSA/ DOX group were all higher than that of $\mathrm{DOX} \cdot \mathrm{HCl}$ at time intervals $2 \mathrm{~h}, 4 \mathrm{~h}$ and $8 \mathrm{~h}$, which were in accordance with the semi-quantitative results (Figure $3 \mathrm{~B})(* p<0.05)$. Micelle-loaded DOX was internalized slightly after $2 \mathrm{~h}$ and with incubation prolonging, internalized DOX started to spread among mammosphere cells. As shown in the XY plane graph (Figure $3 \mathrm{C}$ ), DOX $\cdot \mathrm{HCl}$ showed limited penetration to the outer few cell layers with dispersive diffusion. On the contrary, micelle-loaded DOX efficiently penetrated to the core and mostly distributed in the channel between cells. DOX $\cdot \mathrm{HCl}^{\prime}$ 's diffusion, which mainly depends on concentration gradient, may be restricted by physical barriers of cell-cell and cell-matrix interactions. Furthermore, rapid uptake, ardent DNA binding capacity and sequestration in acidic endosomes also restricted its penetration to the periphery layers [15]. While, the relatively slow cellular internalization of CSOSA contributed to a decreased cellular consumption of micelle-loaded DOX. Furthermore, lipophilic SA on the surface (so-called minor core) [10] and the positive charge enabled the micelle strongly interact with cell membrane, which could drag micelles to the membrane of more inner cells. In consideration that CSCs were usually harbored in the center of a tumor [16], taking the DDS as a strategy would be accessible for drugs to reach them. For direct observation of the internal drug distribution, 3D crosssectional images (Figure 3D) and videos (Supplementary materials) were showed. The fluorescence intensity weakened from the outer side to the inside core.

\section{Enhanced mammosphere suppression in CSOSA/DOX group}

Since the regular MTT assay has a limitation of passing through cells in periphery layers and reacting with internal ones (Supplementary Figure S3), an acid phosphatase (APH) assay was adopted for detection of all mammosphere cells with the addition of Triton-X-100. Blank CSOSA at relevant concentrations showed barely cytotoxicity (Figure 4A), which indicated its safety. DOX encapsulated in CSOSA showed enhanced suppression effect with a decrease of $\mathrm{IC}_{50}$ value from $2.64 \mu \mathrm{g} / \mathrm{mL}$ 
to $1.07 \mu \mathrm{g} / \mathrm{mL}(* p<0.05)$. The reason for stronger CSOSA/DOX suppression effect may due to its increased intracellular concentration. And also CSOSA hold the potential to gather into cell nucleus [17] where DOX mainly works. It could also avoid the efflux by $\mathrm{ABC}$ transporters which highly expressed in breast CSCs. In contrast, $\mathrm{DOX} \cdot \mathrm{HCl}$ could be recognized and excluded. In the curve, it's interesting to see that the survival rate of the first two points rose above $100 \%$, which may be attributed to the released prostaglandin E2. It was produced by chemotherapy damaged cells and could recruit CSCs into cell division [18].

For direct evaluation, spheroid visualization was introduced. Mammospheres without any drug treatment were bright with a distinct border and cells tightly bonded with each other (Figure 4B). While, the CSOSA-treated mammospheres resembled the control except for a reduced refractivity. Cells began to shrink and fall apart in $\mathrm{DOX} \cdot \mathrm{HCl}$ and CSOSA/DOX treated groups; more shed and broke up in the latter group, indicating an enhanced suppression effect of CSOSA/DOX on breast CSCs.

\section{Obvious distinction between MCF-7 and MCF-7 CSCs induced orthotopic xenograft tumors}

CSCs have strong tumorigenicity with as little as 100 cells [19]. However, few studies had reported the difference between tumors induced by CSCs and normal cancer cell lines. In this study, mammosphere cells and MCF-7 cells were inoculated under the mammary gland, respectively. Volumes of $\mathrm{MCF}-7$ tumor grew up to $200 \mathrm{~mm}^{3}$ approximately 10 days after injection of MCF-7 cells and the MCF-7 CSCs tumors retarded for a few days. Tumors reaching $500 \mathrm{~mm}^{3}$ were applied to explore their distinctions. However, special higher expression of $\mathrm{CD}_{4} 4^{+} /$ CD24- cells was not distinguished from CSCs tumor cells, similar to what was reported [20]. Interestingly, cells digested off from the tumors displayed different morphology (Figure 5A). According to the conventional FCM FSC/SSC analysis, where values for $\mathrm{X}$ mean and $\mathrm{Y}$ mean respectively represented cell diameter and internal granularity, the MCF-7 tumor cells were bigger in size and with fewer organelles. As shown in the microscope photos, they were perfectly round and uniform. On the contrary, morphology of CSCs tumor cells was diverse with round, polygonal or rectangular shapes, which suggested that the cells differed within the CSCs tumor model. The stem-like cells (CD44 ${ }^{+} / \mathrm{CD} 24^{-}$cells), accounting for $36.51 \%$ in mammospheres, may attribute to the diverse cell types. Just as that in the serial tumorigenicity assay, CSCs could generate new tumors containing additional CSCs as well as phenotypically diverse mixed populations of non-CSCs, which made them resemble the primary tumors $[19,21]$.

To figure out whether the drug resistance capacity was still maintained after inoculation, expression of ABCG2 protein was explored. From Figure 5B, we found

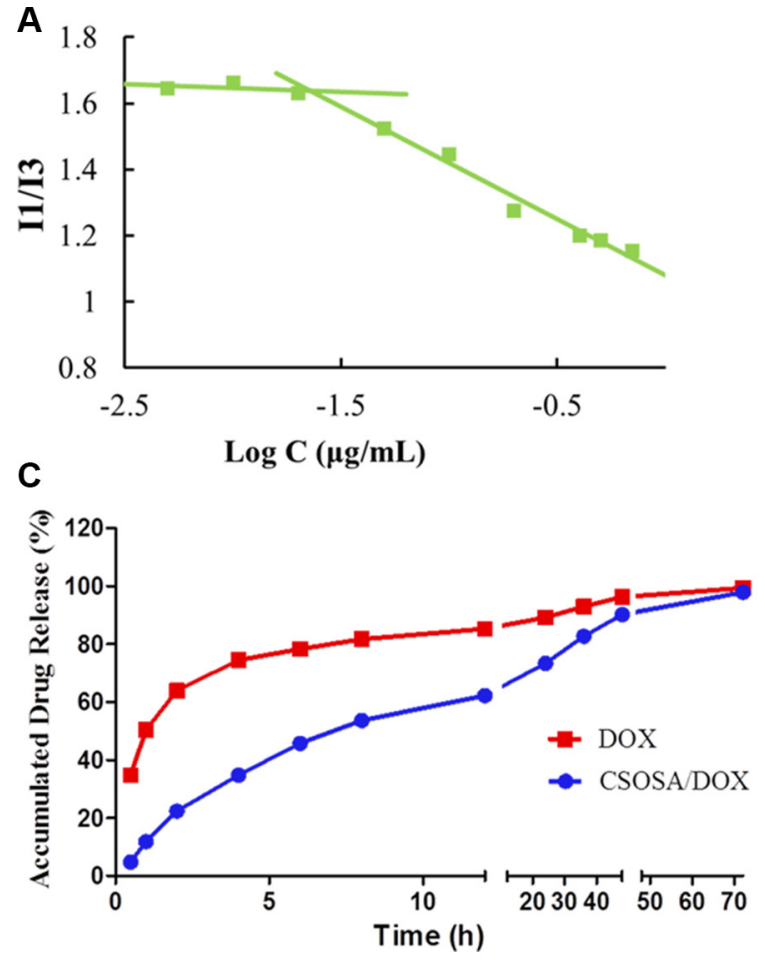

B
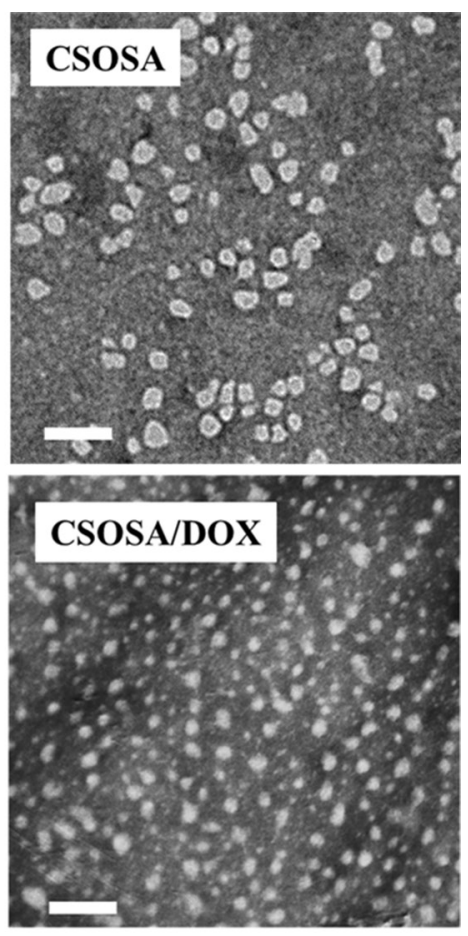

Figure 1: Characteristics of CSOSA and CSOSA/DOX micelles. (A) The I1/I3 ratio of fluorescence intensity of pyrene against logarithm concentrations of CSOSA. (B) TEM images of the micelles. Scale bar, $200 \mathrm{~nm}$. (C) In vitro DOX release profile of CSOSA/DOX micelles and DOX in PBS $(n=3)$. 
that MCF-7 CSCs tumors showed brighter red fluorescence meaning more ABCG2 proteins in the early state, which would equip the tumor with feature of drug resistance. It's worth noting that many cancers in the clinic had intrinsic resistance, not acquired resistance capacity. The structure of surrounding breast tissue was also changed, showing more ductal elements in the specific mammary gland conformation (Figure 5C). The increased ductal branching is usually related to mammary tissue remodeling. Previous research had demonstrated that between non-CSCs and CSCs, only the CSC fraction remodeled the stroma environment [22]. This provided additional evidence for the stemness property of mammospheres. With more ductal elements, the basement membrane would block access of DDS [23]. However, the effect of remodeling in tumor still remains to be estimated. The CSC tumor structure was also special with cell clusters surrounded by collagen (Figure 5D) and the whole structure was portrayed in Figure 5E. These properties collectively demonstrated that the MCF-7 CSC-induced orthotopic xenograft model, different from $\mathrm{MCF}-7$, recapitulated the complexity of primary tumors, with tumor heterogeneity, drug resistance ability and ductal elements.

As to in vivo preclinical research, a proper tumor model is always of vital importance and also a major stumbling block. The preclinical knowledge has been acquired principally from cell line-derived xenografts or patient-derived xenografts (PDXs). However, the cell linederived xenografts are poorly predictive due to genetic drift and losses of tumor heterogeneity [24] and PDXs are cumbersome and costly [25]. The CSC orthotopic xenograft model could meet the above requirements. Additionally, orthotopic organ environment could avoid the formation of skin ulcerations [26], which is benefit for long-term experiment. Above all, this provided a useful platform of tumor model for studying DDS.

\section{Blocking tumor repopulation by CSOSA/DOX}

Multi-cycle repetitive administration was designed to simulate clinical regimen. Tumor naturally expanded exponentially from beginning to end in the glucose group (Figure 6A). Following the guidelines of the Institutional Animal Care and Use Committee, mice were sacrificed when their tumor volumes reached $4000 \mathrm{~mm}^{3}$. Significant enhanced antitumor activity was observed in the $\mathrm{DOX} \cdot \mathrm{HCl}$ and CSOSA/DOX groups compared to the glucose group $(* * p<0.01)$. The whole growth of the two groups showed no significant difference $(p>0.05)$, whereas when analysed separately by cycles it tended the other way (1st, 2nd, 3rd cycle; $p>0.05, * * * p<0.001$, $* * p<0.01)$. Although tumors treated with $\mathrm{DOX} \cdot \mathrm{HCl}$ was small and grow rather slowly, it continued expanding all the time and showed an accelerated repopulation
A

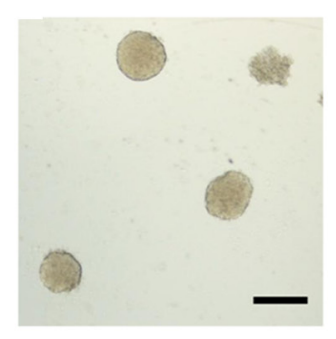

B

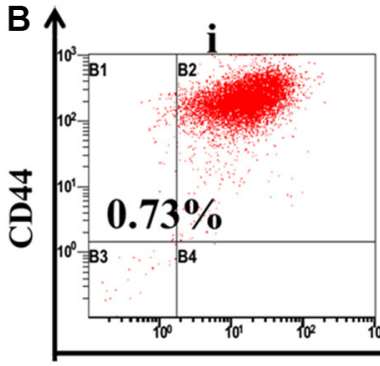

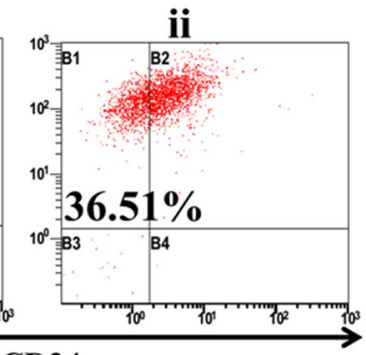

CD24
C

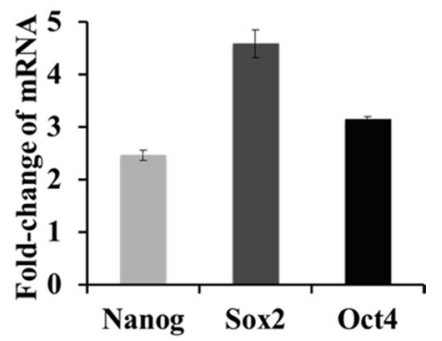

D

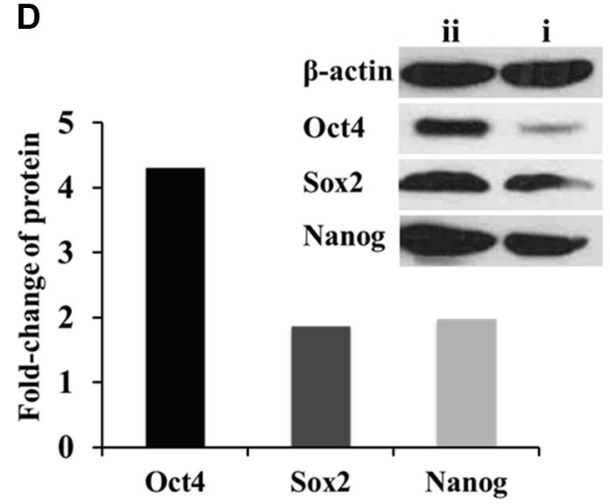

E

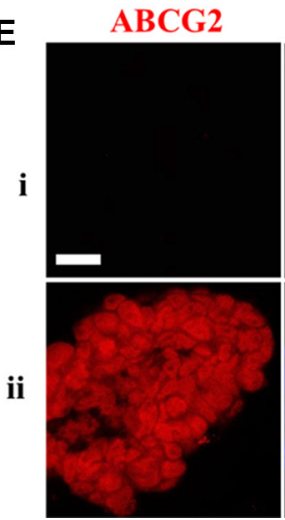

Nucleus

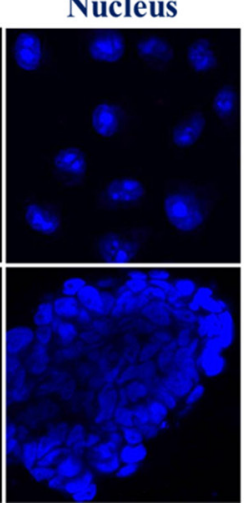

$\mathbf{F}$

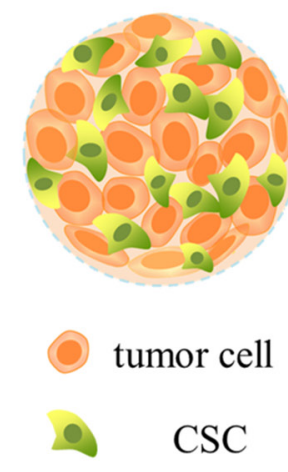

Figure 2: Enrichment of CSCs in mammospheres. (A) Typical photograph of the mammospheres. Scale bar, $200 \mu \mathrm{m}$. i for MCF-7 cells and ii for mammospheres. (B) CD44+/CD24- cells measured by FCM. (C) mRNA fold change of OCT4, SOX2 and Nanog genes after SFM culture $(n=3)$. (D) Fold change of the three proteins. Above: western-blot analysis; below: semi-quantitative analysis by Image J software. (E) CLSM for immunostain of ABCG2 (red). Scale bar, $20 \mu \mathrm{m}$. (F) Schematic diagram of the mammospheres. 
at the start of the successive cycle after the intervals (Supplementary Figure S4). The spaced treatments were intended for recovery of normal tissue, however tumors also recovered and proliferated. The CSOSA/DOX showed a weaker or retardant antitumor effect in the 1 st cycle (the first $21 \mathrm{~d}$ ), which may be attributed to the slower uptake and release rate of DOX. But it stopped growing since the second cycle. Compared to DOX $\cdot \mathrm{HCl}, \mathrm{CSOSA} /$ DOX showed superior antitumor activity since 2 nd cycle, maintaining a stable size without repopulation. The tumor suppression effect of CSOSA/DOX could compete with that of $\mathrm{DOX} \cdot \mathrm{HCl}$ and be more effective for the perspective of long-term chemotherapy.

To see the internal growth status, tumors at the end of each cycle were stained with hematoxylin and eosin (H\&E). Normal tumor cells had large blue nucleus, whereas, the chromatin of necrotic cells became absent with only cytoplasm stained red. Degree of necrosis, to some extent, represented therapeutic efficiency. The negative group showed the largest and thickest living area (Figure 6B) and its necrosis was probably due to a deficit supply caused by rapid growth. Large necrosis areas were observed in the other two groups, and larger in CSOSA/
DOX group, where necrosis level became higher with treatment time prolonging. However, in the $\mathrm{DOX} \cdot \mathrm{HCl}$ group there were always blue areas inside the tumor, revealing vigorous regrowth ability.

\section{Better prognosis in CSOSA/DOX- treated tumors}

Since CSCs were responsible for cancer progression, recurrence and metastasis, the treated tumors were extracted to detect its variation of the $\mathrm{CD} 44^{+} / \mathrm{CD} 24^{-}$cell percentage. As indicated in Figure $6 \mathrm{C}$, the $\mathrm{CSC}$ s proportion of $\mathrm{DOX} \cdot \mathrm{HCl}$ group was remarkably increased with a proportion of $69.36 \%$, seven-fold of that in glucose and CSOSA/DOX groups (10.95\% and $10.62 \%)$. This suggested the CSOSA/DOX would not lead to CSCs enrichment and killed nonCSCs and CSCs indiscriminately, which was essential in tumor therapy [27], because the non-CSCs could transform into CSCs and further sustain tumor growth $[28,29]$. Actually in the CSOSA/DOX group, the tumor volume was much smaller, thus the real number of CSCs was far less.

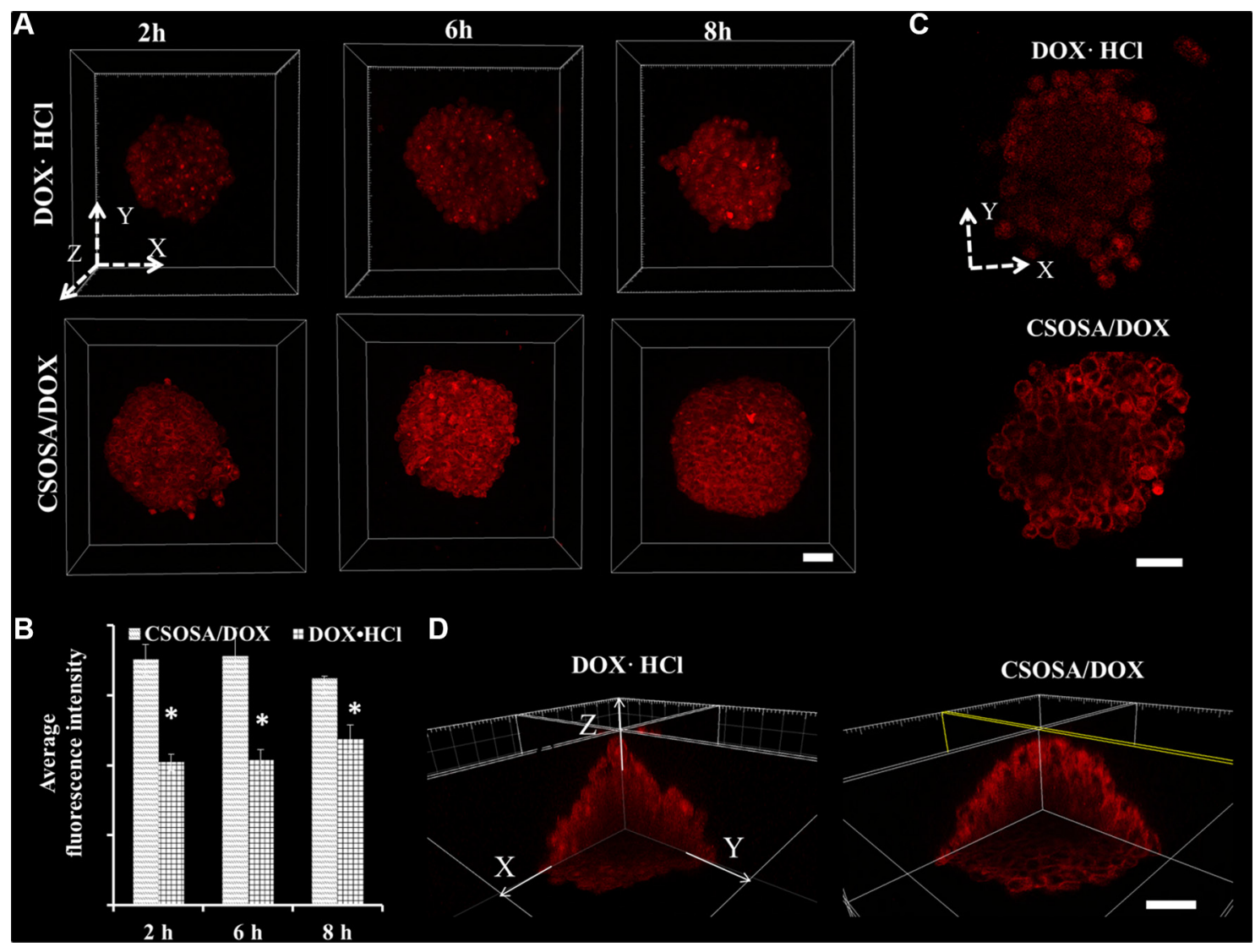

Figure 3: Enhanced uptake of DOX delivered by CSOSA micelles. (A) Z-stack images of DOX uptake in mammospheres. The arrows marked with X, Y and Z indicated three directions and the images were piled up by XY plane in the Z direction. (B) Semiquantitative analysis of fluorescence intensity in A images calculated by MetaMorph software $\left({ }^{*} p<0.05\right)$. (C) Sheets of XY planes (Z coordinate: $60 \mu \mathrm{m}$ ). Thickness of the planes was $4.8 \mu \mathrm{m}$ approximating the diameter of a cell. (D) Internal cross-sectional view of XY, YZ and XZ planes. Scale bar, $50 \mu \mathrm{m}$. 
After pulsed stimulation for three cycles, it was quite understandable for tumors to express increased ABCG2 protein (Figure 6D). ABCG2 was firstly found in the second cycle (Supplementary Figure S5D), implying that the acquiring process needed time. On the contrary, no ABCG2 was found in the other two groups meaning no acquired resistance occurred. Pictures of apoptosis were taken at the non-necrotic area, in case being affected by the necrotic cells. Apoptosis randomly occurred in the glucose group; more apoptotic areas were obviously observed in CSOSA/DOX group compared to $\mathrm{DOX} \cdot \mathrm{HCl}$ group.

The CSOSA/DOX group exhibited smallest living area but strongest apoptosis as well as weakest drug resistance, suggesting a better therapeutic effect. As for $\mathrm{DOX} \cdot \mathrm{HCl}$, many factors related to its ever growing.
Initially, the CSCs tumor model at the early stage was drugresistant and $\mathrm{DOX} \cdot \mathrm{HCl}$ can be extruded. Subsequently, tumors got stronger resistance capacity with $\mathrm{DOX} \cdot \mathrm{HCl}$ pulse simulation and become more difficult to kill. Another reason for its repopulation was the remaining $\mathrm{CD}_{4} 4^{+} /$ $\mathrm{CD} 24^{-}$cells which reserved the ability to proliferate, differentiate and ultimately facilitated tumor growth.

\section{Microenvironment damage caused by CSOSA/ DOX}

CSC niche was further explored to explain the suppression effect. Except for supporting tumor cells, microenvironment also acted as barriers hindering delivery of nanoparticles. The dense collagen matrix
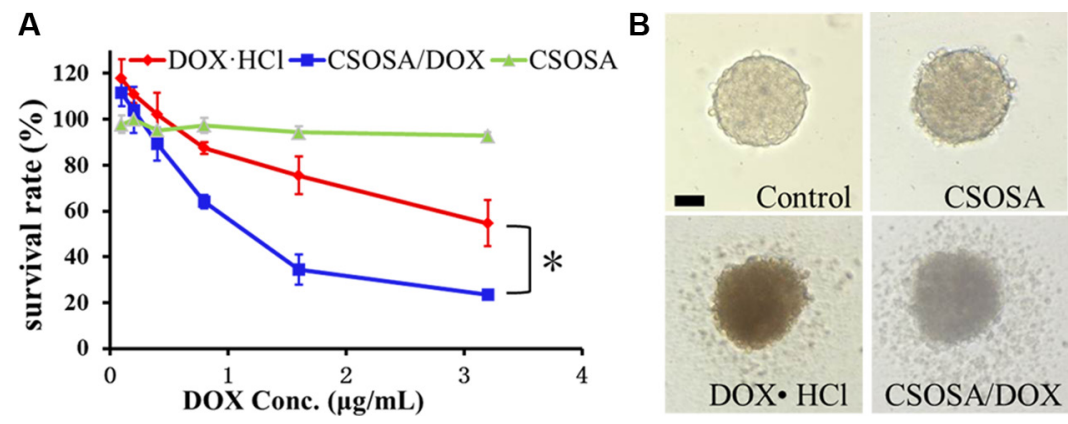

Figure 4: Cytotoxicity of CSOSA/DOX against mammospheres. (A) The survival rates of the mammospheres measured by APH assay. ${ }^{*} p<0.05, n=3$. (B) Typical light photographs of mammospheres treated with formulations (CSOSA, DOX $\left.\cdot \mathrm{HCl}, \mathrm{CSOSA} / \mathrm{DOX}\right)$. The equivalent dose of DOX was $1.5 \mu \mathrm{g} / \mathrm{mL}$. Scale bar, $50 \mu \mathrm{m}$.
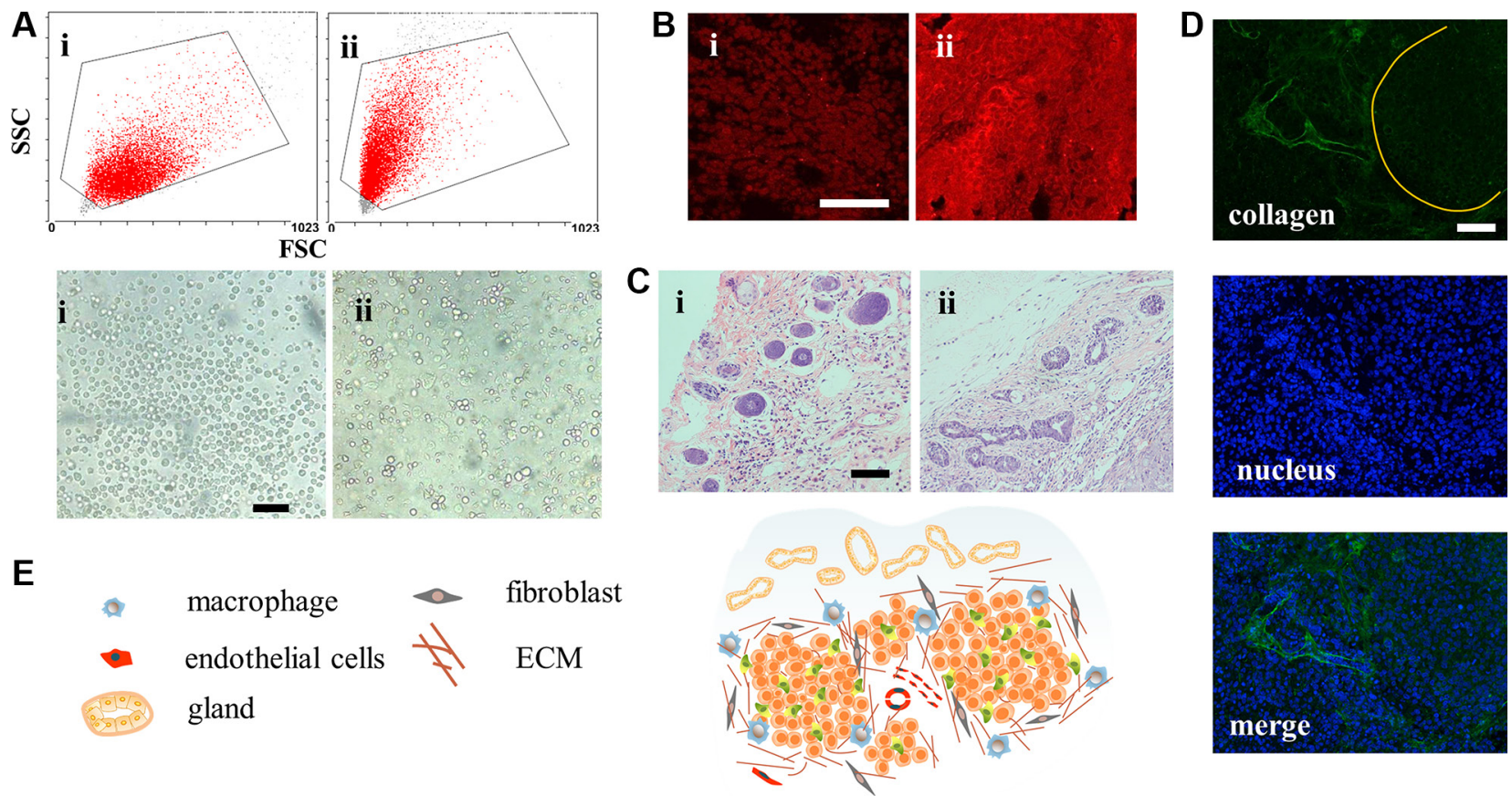

Figure 5: Structure of the CSCs induced orthotopic xenograft tumor model. (A) Conventional FCM FSC/SSC analysis and light photographs of the tumor cells. Scale bar, $50 \mu \mathrm{m}$. i for MCF-7 cells and ii for mammospheres. (B) CLSM for immunostain of ABCG2 (red). Scale bar, $100 \mu \mathrm{m}$. (C) H\&E stain images of the mammary tissue on the peripheral region of the tumors. Scale bar, $200 \mu \mathrm{m}$. (D) The clusters of tumors were surrounded and separated by collagen. (E) Structure and cell components scheme of CSCs-induced orthotopic tumor. 
reduced vascular perfusion through elevated interstitial fluid pressure and compressing tumor vessels [30-32], and thus resulted in suboptimal outcomes [33]. As shown in Figure 7, after treated by CSOSA/DOX, vessels became bigger and more. This would enlarge the vascular perfusion for more drug distribution. Generally, free chemicals are unable to penetrate more than 40-50 $\mu \mathrm{m}$ from vessels because of extracellular matrix, let alone the distance between tumor cells and vessels was often more than $100 \mu \mathrm{m}$ [34]. However, CSOSA/DOX resulted in lower collagen levels and made it easy to penetrate and to reach tumor cells. In addition, the particle size of the micelle was appropriate for tumor penetration, as previous research reported only micelles of $30 \mathrm{~nm}$ could penetrate in poorly permeable pancreatic tumors among different sizes [35]. While, in $\mathrm{DOX} \cdot \mathrm{HCl}$ group, tumor vessels were squeezed by dense collagen. The situation was the same at the end of each chemotherapy cycle (Supplementary Figure S5A-S5C) and the collagen grew more and more tense. Furthermore, the destroyed microenvironment, niche for CSCs, could no longer modulate the transformation of CSCs to non-CSCs [36]. Tumor cells to some extent were harbored and protected by secreted collagen. After treated by CSOSA/DOX, shield for tumor cell was lost. Thereby the chemotherapy was potentiated.

To figure out the leading cause of decreased collagen level, cancer-associated fibroblast (CAF), secreting collagen in tumors [37], was traced (Figure 7B). Interestingly, CAFs in CSOSA/DOX showed dispersed distribution and was of low content. It implied that the CAF was an acting target of CSOSA/DOX. On the contrary, tumors in $\mathrm{DOX} \cdot \mathrm{HCl}$ group were abundant of CAFs and clusters of tumor cells were separated by them.

\section{Reduced systemic toxicity of DOX by CSOSA micelles}

Besides therapeutic efficacy, safety was another important therapy index. Low cytotoxicity was undoubtedly a huge advantage especially with this longterm administration. The body weight decreased after administration of drugs (Figure 8). Mice in CSOSA/ DOX group could always recover during the intervals. While mice in the $\mathrm{DOX} \cdot \mathrm{HCl}$ group would only regain a bit and this regain get less and less as chemotherapy time extended. To further characterize its toxicity, a

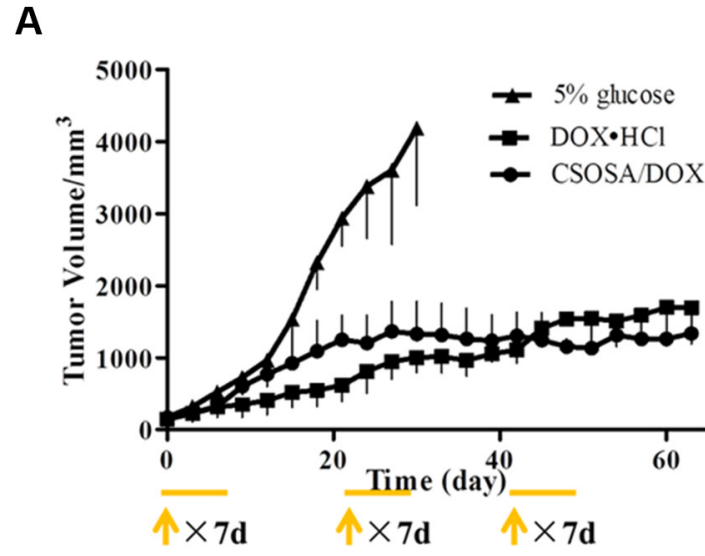

D
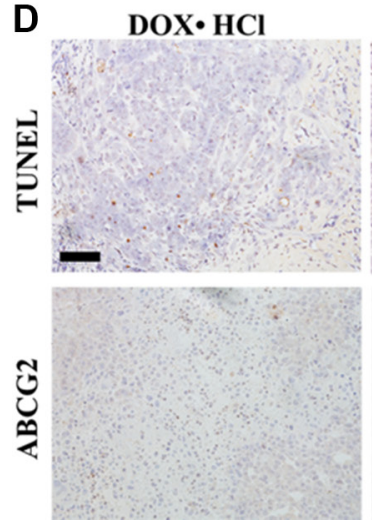

\section{CSOSA/DOX}

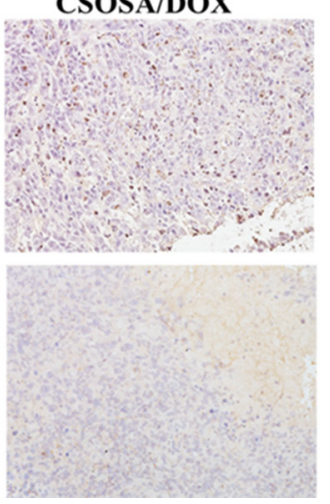

B

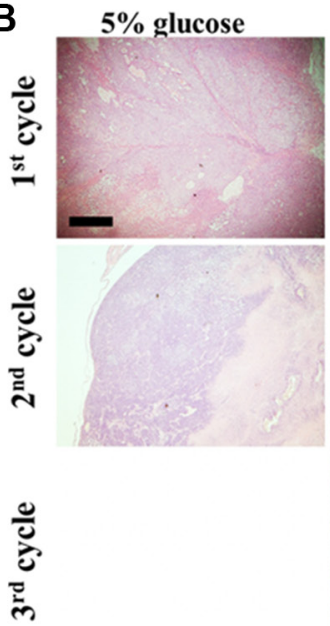

C

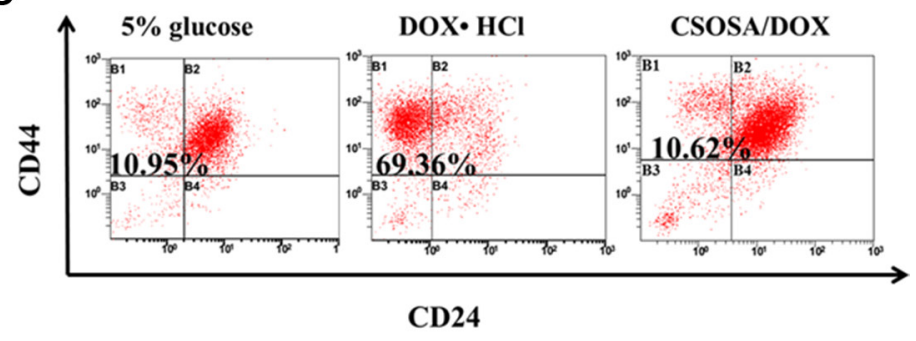

Figure 6: Tumor repopulation blocking effect of CSOSA/DOX. (A) Tumor growth curve after injection of the formulations $(n=4)$. The start of each treatment cycle was noted with arrows and each administration cycle last for $7 \mathrm{~d}$. (B) H\&E analysis of tumors at the end of each cycle. The pink area represented necrosis. Scale bar, $500 \mu \mathrm{m}$. (C) FCM histograms of the CD44 ${ }^{+} / \mathrm{CD}^{2} 4^{-}$cells in B1 section. (D) TUNEL was for apoptosis and ABCG2 stain for drug resistant capacity. Scale bar, $200 \mu \mathrm{m}$. 


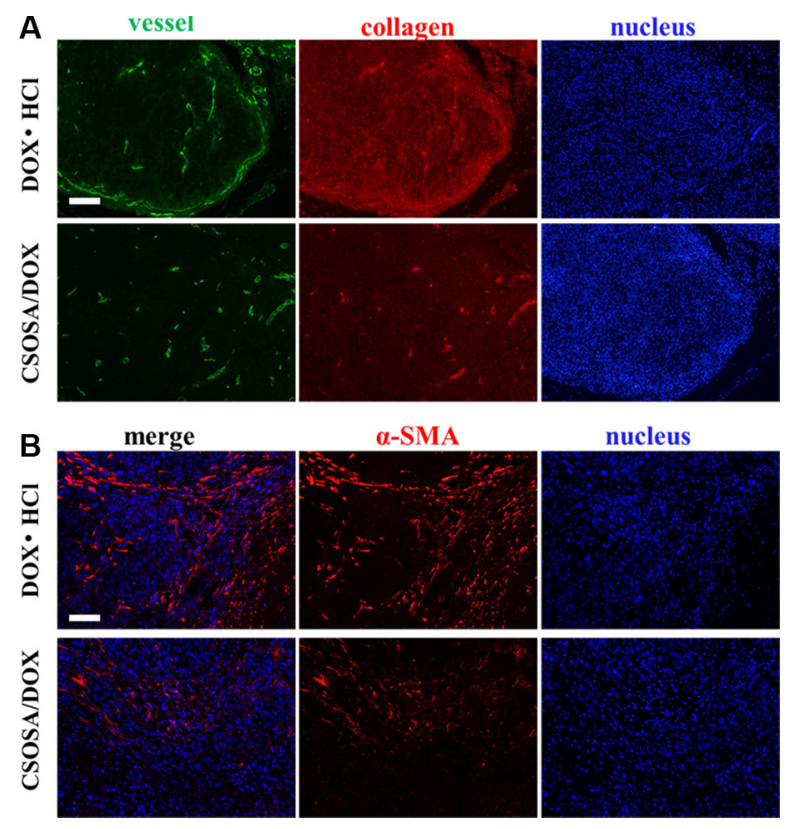

Figure 7: Damage to the microenvironment caused by CSOSA/DOX. (A) Representative images from immunofluorescence stain of tumor vessels (green) and collagen (red). (B) Immunofluorescence images of CAF ( $\alpha$-SMA, red). The CAFs in the DOX $\cdot \mathrm{HCl}$ group was more highly and separated the tumor cells into clusters. Scale bar, $200 \mu \mathrm{m}$.
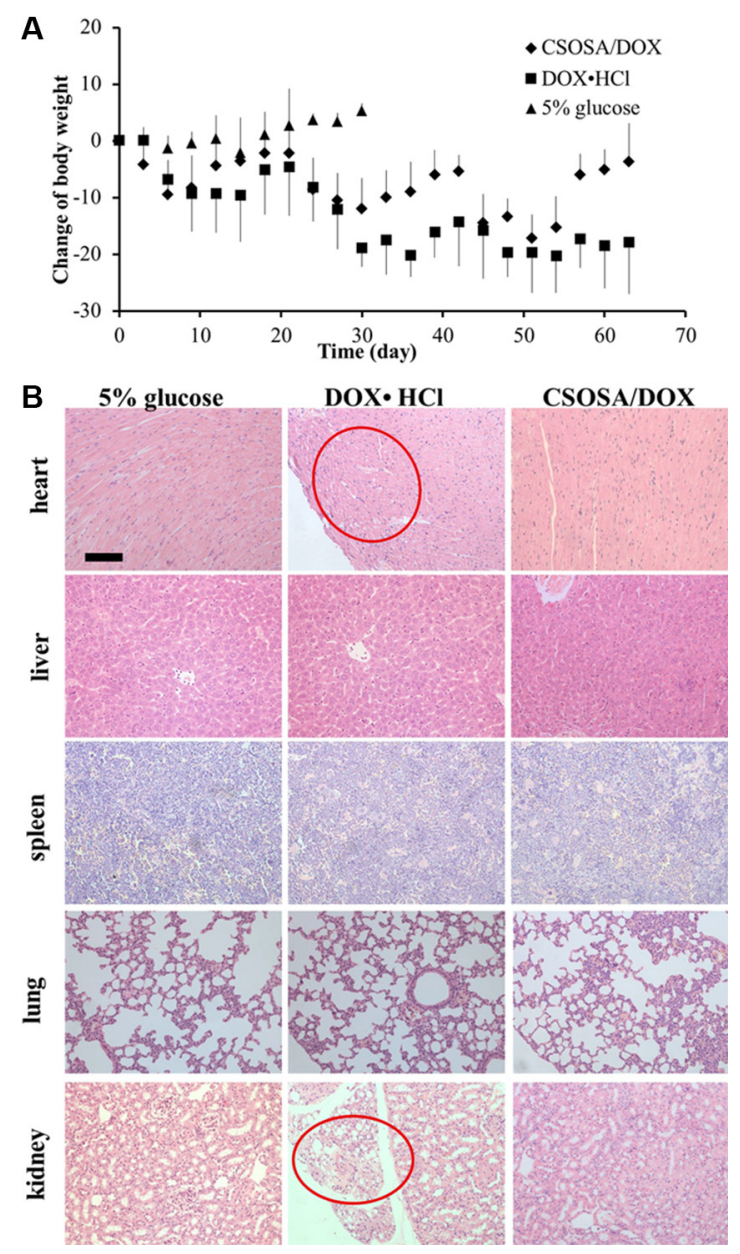

Figure 8: Systemic toxicity caused by DOX. (A) Changes of body weights with repetitive administration of three formulations. (B) $\mathrm{H} \& \mathrm{E}$ analysis of the organs at the end of the treatment. Myofibrillar loss in hearts and vacuoles in kidneys were indicated by the red cycles. 
histopathological examination of internal organs was applied. Slight extramedullary hematopoiesis was found in all liver and spleen because of long-term burden with tumor. Organs of CSOSA/DOX-treated mice maintained regular cell distribution and normal architecture. However, irregular cell arrangement and myofibrillar loss in hearts and vacuoles in kidneys were serious in the $\mathrm{DOX} \cdot \mathrm{HCl}$ group (Figure $8 \mathrm{~B}$ ). For the CSOSA micelles alone, the chitosan oligosaccharide was biodegradable, biocompatible and non-toxic material. The reduced systemic toxicity of DOX encapsulated could be credited to the changed distribution by CSOSA micelles.

\section{MATERIALS AND METHODS}

\section{Materials}

Chitosan oligosaccharide (CSO, Mw $=18 \mathrm{kDa}$, 95\% deacetylated degree) was obtained by enzymatic degradation of chitosan $(\mathrm{Mw}=450.0 \mathrm{kDa})$ supplied by Yuhuan Marine Biochemistry Co., Ltd. Stearic acid (SA) was purchased from Aladdin Industrial Inc. DOX was purchased from Hisun Pharmaceutical Co., Ltd. Insulin and immunopure p-nitrophenyl phosphate were purchased from Sigma Chemical Co. EGF and bFGF was purchased from Peprotech. RNAiso Plus, PrimeScriptTM RT reagent Kit and SYBR ${ }^{\circledR}$ Premix Ex TaqTM were purchased from TaKaRa Biotechnology (Dalian) Co., Ltd. SOX2, NANOG and OCT4 antibodies were purchased from ABGENT.

MCF-7 cells were obtained from Cell Resource Center of China Science Academe. Female BALB/c nude mice (6-8 weeks old) were purchased from Shanghai Silaike Laboratory Animal Limited Liability Company. The mice were raised in the specific pathogen-free level animal facility and freely allowed access to food and water.

\section{Synthesis of CSOSA and preparation of CSOSA/DOX}

CSOSA was fabricated via the reaction of the carboxyl group of SA with the amine group of CSO in the presence of 1-ethyl-3-(3-dimethylaminopropyl) carbodiimide (EDC) as reported [10]. Briefly, SA (0.120 g) and $\operatorname{EDC}(0.430 \mathrm{~g})$ dissolved in $18 \mathrm{~mL}$ ethanol were maintained at $60^{\circ} \mathrm{C}$ to activate the carboxyl group. CSO $(0.5 \mathrm{~g})$ dissolved in $36 \mathrm{~mL}$ distilled water was pre-heated followed by addition of the activated mixture. After stirred at $60^{\circ} \mathrm{C}$ overnight, the final reaction mixture was dialyzed against distilled water. Then, the lyophilized product was dispersed in ethanol to remove the unreacted SA by filtration. The CSOSA was received after lyophilized.

DOX-loaded micelles were prepared by dialysis. Briefly, a solution of DMSO containing DOX was dropped in the micelle solution and stirred for $1 \mathrm{~h}$, followed by dialysis against distilled water (Milli-Q, Millipore) overnight. Then, the unencapsulated DOX was removed by centrifugation at $8000 \mathrm{rpm}$ for $10 \mathrm{~min}$ (3K30, Sigma Laborzentrifugen).

\section{Characterization of CSOSA and CSOSA/DOX}

The average particle diameter and size distribution of blank micelles and DOX-loaded micelles were measured by a dynamic light scattering (DLS) Zetasizer (3000HS, Malvern Instruments Ltd, UK). The samples were placed on copper grids and stained with $2 \%(\mathrm{w} / \mathrm{v})$ phosphotungstic acid for viewing by a transmission electron microscopy (TEM, JEM-1230, Japan). The critical micelle concentration (CMC) of the CSOSA was determined by pyrene fluorescence method using a fluorometer (F-2500, Hitachi Co., Japan). Pyrene $\left(6.0 \times 10^{-7} \mathrm{~mol} / \mathrm{L}\right)$ was pre-dried and CSOSA solutions were added and sonicated together for $30 \mathrm{~min}$. The excitation wavelength was set as $337 \mathrm{~nm}$ and the emission wavelength was scanned.

In vitro cumulative release of $\mathrm{DOX}$ from the micelles was investigated in PBS. First, $1 \mathrm{~mL}$ CSOSA/ DOX solution was introduced into a dialysis membrane (MWCO $=3.5 \mathrm{kDa}$, Spectrum Labs, USA) with ends sealed and submerged into $20 \mathrm{~mL}$ release medium. The system was stirred at $60 \mathrm{rpm}$ and maintained at $37^{\circ} \mathrm{C}$. Samples were withdrawn at predetermined times $(1 \mathrm{~h}$, $2 \mathrm{~h}, 4 \mathrm{~h}, 6 \mathrm{~h}, 12 \mathrm{~h}, 24 \mathrm{~h}, 36 \mathrm{~h}$ and $48 \mathrm{~h}$ ) from the release medium. The concentrations of released DOX were determined by a fluorometer. As control, dispersion of DOX was conducted under the same condition.

\section{Formation of mammospheres}

A single-cell suspension of MCF-7 cells suspended at a density of $5 \times 10^{3}$ cells $/ \mathrm{mL}$ in serum free medium (SFM) was inoculated in ultra-low-attachment plates. The SFM was DMEM/F12 medium supplemented with human recombinant epidermal growth factor $(20 \mathrm{ng} / \mathrm{mL})$, recombinant basic fibroblast growth factor $(20 \mathrm{ng} / \mathrm{mL})$, $5 \mu \mathrm{g} / \mathrm{mL}$ insulin and 2\% B27 supplement. The cells were cultured for about $10 \mathrm{~d}$ in an incubator at $37^{\circ} \mathrm{C}$ in humidified $5 \% \mathrm{CO} 2$ atmosphere. The medium was added every $5 \mathrm{~d}$.

\section{Flow cytometry}

Mammospheres were trypsinized into single-cell suspension with Accutase-Enzyme Cell Detachment Medium, and then washed and resuspended in PBS. Single cells were labeled with antibodies specific for human cells: anti-CD24-FITC and anti-CD44-PE (BD PharmingenTM). An unstained, single stain served as the control. Isotype controls were used to exclude non-specific conjunctions. After being incubated with antibodies for $30 \mathrm{~min}$ at $4^{\circ} \mathrm{C}$ in the dark, the unbound antibody was washed. Cells were fixed for analysis (FC500MCL, Beckman Coulter, USA). 
For tumor analysis, harvested tumors were minced to form single cell suspension. The tissue lysate was filtered through a 200 mesh sieve prior to stain. Surface antigen CD24 and CD44 were detected as above. The single cell suspension was also observed under a light microscope.

\section{Real-time polymerase chain reaction}

Total RNA was extracted by TRIzol reagent (Gibco BRL, Gaithersburg, MD) according to the manufacturer's protocol. Nucleic acid concentrations were measured at $260 \mathrm{~nm}$ (Nanodrop2000 Spectrometer). One microgram of RNA sample was reverse transcribed to cDNA with the PrimeScript ${ }^{\mathrm{TM}}$ RT Reagent Kit. The cDNA synthesis condition was $37^{\circ} \mathrm{C} 15 \mathrm{~min}$ and $85^{\circ} \mathrm{C} 5 \mathrm{~s}$. A master mix for each PCR run was prepared with SYBR ${ }^{\circledR}$ Premix Ex Taq ${ }^{\mathrm{TM}}$ reagent. Appropriately diluted cDNA was added with the primers (sequences shown in Supplementary Table S1). The PCR condition was $94^{\circ} \mathrm{C}$ for $3 \mathrm{~min}$ to denature the RNA/cDNA hybrid, then 40 cycles of $94^{\circ} \mathrm{C}$ for $1 \mathrm{~min}$, $45^{\circ} \mathrm{C}$ for $1 \mathrm{~min}$, and $72^{\circ} \mathrm{C}$ for $1 \mathrm{~min}$. All samples were amplified in triplicate (StepOneTM, Applied Biosystems, USA). The comparative cycle threshold (CT) $\left(2^{-\Delta \Delta C T}\right)$ method was used to determine the relative expression.

\section{Western blot analysis}

The MCF-7 cells and mammospheres were mixed with sample loading buffer, destroying the cell membrane with pipette tip, boiled for $15 \mathrm{~min}$ and then separated by Tris-Tricine SDS-PAGE. Proteins were electrophoretically transferred to nitrocellulose membranes and blocked with skim milk in PBS containing 0.05\% Tween 20 for $1 \mathrm{~h}$. After we washed the membrane, the antibodies of Nanog, OCT4 and SOX2 were added and incubated for $4 \mathrm{~h}$ at room temperature. The bound antibodies were detected by horseradish peroxidase-conjugated $\operatorname{IgG}$ secondary antibodies. Signals were developed via an enhanced chemiluminescence detection system.

\section{Uptake of DOX $\cdot \mathrm{HCl}$ and CSOSA/DOX in mammospheres}

Mammospheres approximately $200 \mu \mathrm{m}$ in diameter were incubated with $\mathrm{DOX} \cdot \mathrm{HCl}$ and CSOSA/DOX. The images were collected on a confocal laser scan microscopy (CLSM) (BX61W1-FV1000, Olympus) with a 40× water immersion objective. Laser beam with $546 \mathrm{~nm}$ excitation wavelength was used for DOX. Z-stack images were obtained by scanning the mammospheres layer by layer. Each scanning layer was $1.2 \mu \mathrm{m}$ in thickness, and the total scanning was approximately $100 \mu \mathrm{m}$ in depth.

\section{Mammosphere suppression measured by APH assay}

The in vitro cytotoxicity was evaluated by APH assay with minor modification [38, 39]. Mammospheres grew in 96-well plates with $150 \mu \mathrm{L}$ medium was incubated with CSOSA, DOX $\cdot \mathrm{HCL}$ and CSOSA/DOX for $48 \mathrm{~h}$, followed by centrifugation to spin down and washing with PBS. The supernatant was discarded to a final volume of $100 \mu \mathrm{L}$. Then, $100 \mu \mathrm{L}$ of the assay buffer $(0.1 \mathrm{M}$ sodium acetate, $0.1 \%$ Triton-X-100, $1 \mathrm{mg} / \mathrm{mL}$ immunopure p-nitrophenyl phosphate (Sigma)) was added and incubated for $90 \mathrm{~min}$ at $37^{\circ} \mathrm{C}$. After supplemention of $10 \mu \mathrm{L} \mathrm{NaOH}$ solution, absorption at $405 \mathrm{~nm}$ was measured on a microplate reader (SpectraMax M5, Molecular Devices).

\section{Tumor progression studies}

All of the experiments were performed in compliance with the guidelines established by the Zhejiang University Institutional Animal Care and Use Committee. The mice were treated with estrogen before inoculation. The MCF-7 and mammosphere cells were injected into the mammary fat pad of the 4th nipple. An estradiol supplementation was given every $5 \mathrm{~d}$ until the tumor come up.

Tumor-bearing mice were randomly divided into three groups: $5 \%$ glucose control group, positive control group (DOX $\cdot \mathrm{HCl}, 2 \mathrm{mg} / \mathrm{kg} / \mathrm{d}$ in $0.2 \mathrm{~mL}$ ) and the CSOSA/DOX group (DOX, $2 \mathrm{mg} / \mathrm{kg} / \mathrm{d}$ in $0.2 \mathrm{~mL}$ ). Three chemotherapy cycles were performed and each was $21 \mathrm{~d}$. Drugs were administered intravenously in the first $7 \mathrm{~d}$ of each cycle. The tumor size and body weights were recorded every $3 \mathrm{~d}$. The volume was calculated with the formula: (length) $\times(\text { width })^{2} / 2$. For the analysis of changes between cycles, two more mice were added in each group and sacrificed at the end of each cycle.

\section{Histological analysis}

Tumor and organ samples were fixed in 4\% paraformaldehyde and embedded in paraffin before sectioning at $4 \mu \mathrm{m}$ thickness. H\&E staining was performed as follow: After fixed with ethanol for $20 \mathrm{~min}$, sections were washed and treated with hematoxylin for nuclei staining. Then, after washed, the cytoplasm was counterstained with $1 \%$ eosin solution. Stained sections were embedded in glycerin jelly followed by final water washing.

Immunohistochemistry and immunofluorescence were performed as follow: after fixed with cold acetone, cells were blocked with $2 \%$ goat serum for $2 \mathrm{~h}$. The primary antibody of ABCG2 (collagen type), $\alpha$-SMA, CD31) were applied to samples overnight at $4^{\circ} \mathrm{C}$. After washing, the secondary antibody was incubated for $1 \mathrm{~h}$. Nuclei were stained with DAPI for $10 \mathrm{~min}$. The samples were protected by glycerol and covered by a cover glass.

\section{Statistical analysis}

All of the data were expressed as means \pm standard deviation (SD). Statistical significance was analyzed using Student's $t$-test. $p$ value of $<0.05$ was considered 
statistically significant. $p>0.05$ represents not significant; $* p<0.05 ; * * p<0.01 ; * * * p<0.001$.

\section{ACKNOWLEDGMENTS}

We thank Mrs. Shuangshuang Liu from the Image Center, Zhejiang University School of Medicine for CLSM images and Dr. Karson Putt, Managing Director for the Centre of Drug Discovery at Purdue University for advices on article writing.

\section{CONFLICTS OF INTEREST}

There is no conflicts of interest.

\section{FINANCIAL SUPPORT}

This project was funded by National Natural Science Foundation of China (No. 81473144 and No. 81273442).

\section{REFERENCES}

1. Long GD, Negrin RS, Hoyle CF, Kusnierz-Glaz CR, Blume KG, Chao NJ. Multiple cycles of high dose chemotherapy supported by hematopoietic progenitor stem cells as treatment for patients with advanced malignancies. Cancer. 1995; 76: 860-8.

2. Culine S, Fabbro M, Assens C, Ychou M, Romieu G, Kramar A, Cupissol D, Pingue F, Pujol H. Four-step high-dose sequential chemotherapy with hematopoietic progenitor-cell support as induction treatment for patients with solid tumors. Ann Oncol. 1997; 8:951-6.

3. Kreso A, Dick John E. Evolution of the cancer stem cell model. Cell Stem Cell. 2014; 14:275-91.

4. Mitra A, Mishra L, Li, S. EMT, CTCs and CSCs in tumor relapse and drug-resistance. Oncotarget. 2015; 6:10697-711. doi: 10.18632/oncotarget.4037.

5. Kanehira M, Kikuchi T, Santoso A, Tode N, Hirano T, Ohkouchi S, Tamada T, Sugiura H, Harigae H, Ichinose M. Human marrow stromal cells downsize the stem cell fraction of lung cancers by fibroblast growth factor 10 . Mol Cell Biol. 2014; 34:2848-56.

6. Jang JY, Kim MK, Jeon YK, Joung YK, Park KD, Kim CW. Adenovirus adenine nucleotide translocator-2 shRNA effectively induces apoptosis and enhances chemosensitivity by the down-regulation of ABCG2 in breast cancer stemlike cells. Exp Mol Med. 2012; 44:251-9.

7. Kim S-S, Rait A, Kim E, Pirollo KF, Nishida M, Farkas N, Dagata JA, Chang EH. A nanoparticle carrying the p53 gene targets tumors including cancer stem cells, sensitizes glioblastoma to chemotherapy and improves survival. ACS Nano. 2014; 8:5494-514.

8. Sun S, Liu S, Duan SZ, Zhang L, Zhou H, Hu Y, Zhou X, Shi C, Zhou R, Zhang Z. Targeting the c-Met/FZD8 signaling axis eliminates patient-derived cancer stem-like cells in head and neck squamous carcinomas. Cancer Res. 2014; 74:7546-59.

9. Hu FQ, Liu LN, Du YZ, Yuan H. Synthesis and antitumor activity of doxorubicin conjugated stearic acid-g-chitosan oligosaccharide polymeric micelles. Biomaterials. 2009; 30:6955-63.

10. You J, Hu F-Q, Du Y-Z, Yuan H. Polymeric micelles with glycolipid-like structure and multiple hydrophobic domains for mediating molecular target delivery of paclitaxel. Biomacromolecules. 2007; 8:2450-56.

11. Ravi M, Paramesh V, Kaviya SR, Anuradha E, Solomon FD. 3D cell culture systems: advantages and applications. J Cell Physiol. 2015; 230:16-26.

12. Weiswald LB, Bellet D, Dangles-Marie V. Spherical cancer models in tumor biology. Neoplasia. 2015; 17:1-15.

13. Leis O, Eguiara A, Lopez-Arribillaga E, Alberdi MJ, Hernandez-Garcia S, Elorriaga K, Pandiella A, Rezola R, Martin AG. Sox2 expression in breast tumours and activation in breast cancer stem cells. Oncogene. 2012; 31:1354-65.

14. $\mathrm{Hu} \mathrm{L}, \mathrm{Mc}$ Arthur $\mathrm{C}$, Jaffe RB. Ovarian cancer stem-like side-population cells are tumourigenic and chemoresistant. Br J Cancer. 2010; 102:1276-83.

15. Kim TH, Mount CW, Gombotz WR, Pun SH. The delivery of doxorubicin to 3-D multicellular spheroids and tumors in a murine xenograft model using tumor-penetrating triblock polymeric micelles. Biomaterials. 2010; 31: 7386-97.

16. Ju C, Mo R, Xue J, Zhang L, Zhao Z, Xue L, Ping Q, Zhang C. Sequential intra-intercellular nanoparticle delivery system for deep tumor penetration. Angew Chem Int Ed Engl. 2014; 53:6253-8.

17. Ye YQ, Yang FL, Hu FQ, Du YZ, Yuan H, Yu* HY, Coremodified chitosan based polymeric micelles for controlled release of doxorubicin. Int J Pharm. 2008; 352: 294-301.

18. Kurtova AV, Xiao J, Mo Q, Pazhanisamy S, Krasnow R, Lerner SP, Chen F, Roh TT, Lay E, Ho PL, Chan KS. Blocking PGE2-induced tumour repopulation abrogates bladder cancer chemoresistance. Nature. 2015; 517:209-13.

19. Al-Hajj M, Wicha MS, Benito-Hernandez A, Morrison SJ, Clarke MF. Prospective identification of tumorigenic breast cancer cells. P Natl Acad Sci USA. 2003; 100:3983-88.

20. Wang D, Huang J, Wang X, Yu Y, Zhang H, Chen Y, Liu J, Sun Z, Zou H, Sun D, Zhou G, Zhang G, Lu Y, et al. The eradication of breast cancer cells and stem cells by 8 -hydroxyquinoline-loaded hyaluronan modified mesoporous silica nanoparticle-supported lipid bilayers containing docetaxel. Biomaterials. 2013; 34:7662-73.

21. Cho RW, Wang X, Diehn M, Shedden K, Chen GY, Sherlock G, Gurney A, Lewicki J, Clarke MF. Isolation and molecular characterization of cancer stem cells in MMTVWnt-1 murine breast tumors. Stem Cells. 2008; 26:364-71.

22. Parashurama N, Lobo NA, Ito K, Mosley AR, Habte FG, Zabala M, Smith BR, Lam J, Weissman IL, Clarke MF, 
Gambhir SS. Remodeling of endogenous mammary epithelium by breast cancer stem cells. Stem Cells. 2012; 30:2114-27.

23. Komuro M, Suzuki K, Kanebako M, Kawahara T, Otoi T, Kitazato K, Inagi T, Makino K, Toi M, Terada H. Novel iontophoretic administration method for local therapy of breast cancer. J Control Release. 2013; 168:298-306.

24. Gillet JP, Varma S, Gottesman MM. The clinical relevance of cancer cell lines. J Natl Cancer Inst. 2013; 105:452-8.

25. Marangoni E, Poupon MF. Patient-derived tumour xenografts as models for breast cancer drug development. Curr Opin Oncol. 2014; 26:556-61.

26. Ho KS, Poon PC, Owen SC, Shoichet MS. Blood vessel hyperpermeability and pathophysiology in human tumour xenograft models of breast cancer: a comparison of ectopic and orthotopic tumours. Bmc Cancer. 2012; 12:579-88.

27. Adorno-Cruz V, Kibria G, Liu X, Doherty M, Junk DJ, Guan D, Hubert C, Venere M, Mulkearns-Hubert E, Sinyuk M, Alvarado A, Caplan AI, Rich J, et al. Cancer Stem Cells: Targeting the roots of cancer, seeds of metastasis, and sources of therapy resistance. Cancer Res. 2015; 75:924-29.

28. Gupta PB, Fillmore CM, Jiang G, Shapira SD, Tao K, Kuperwasser C, Lander ES. Stochastic state transitions give rise to phenotypic equilibrium in populations of cancer cells. Cell. 2011; 146:633-44.

29. Nguyen LV, Vanner R, Dirks P, Eaves CJ. Cancer stem cells: an evolving concept. Nat Rev Cancer. 2012; 12:133-43.

30. Fang M, Yuan J, Peng C, Li Y. Collagen as a double-edged sword in tumor progression. Tumour Biol. 2014; 35:2871-82.

31. Lim YZ, South AP. Tumour-stroma crosstalk in the development of squamous cell carcinoma. Int J Biochem Cell Biol. 2014; 53:450-8.

32. Chauhan VP, Martin JD, Liu H, Lacorre DA, Jain SR, Kozin SV, Stylianopoulos T, Mousa AS, Han X,
Adstamongkonkul P, Popovic Z, Huang P, Bawendi MG, et al. Angiotensin inhibition enhances drug delivery and potentiates chemotherapy by decompressing tumour blood vessels. Nat Commun. 2013; 4:2516.

33. Song G, Darr DB, Santos CM, Ross M, Valdivia A, Jordan JL, Midkiff BR, Cohen S, Nikolaishvili-Feinberg N, Miller CR, Tarrant TK, Rogers AB, Dudley AC, et al. Effects of tumor microenvironment heterogeneity on nanoparticle disposition and efficacy in breast cancer tumor models. Clin Cancer Res. 2014; 20:6083-95.

34. Primeau AJ, Rendon A, Hedley D, Lilge L, Tannock IF. The distribution of the anticancer drug Doxorubicin in relation to blood vessels in solid tumors. Clin Cancer Res. 2005; 11:8782-8.

35. Cabral H, Matsumoto Y, Mizuno K, Chen Q, Murakami M, Kimura M, Terada Y, Kano MR, Miyazono K, Uesaka M, Nishiyama N, Kataoka K. Accumulation of sub-100 nm polymeric micelles in poorly permeable tumours depend on size. Nat Nano. 2011; 6:815-23.

36. Borovski T, De Sousa EMF, Vermeulen L, Medema JP. Cancer stem cell niche: the place to be. Cancer Res. 2011; 71:634-9.

37. Cirri P, Chiarugi P. Cancer-associated-fibroblasts and tumour cells: a diabolic liaison driving cancer progression. Cancer Metastasis Rev. 2012; 31:195-208.

38. Friedrich J, Seidel C, Ebner R, Kunz-Schughart LA. Spheroid-based drug screen: considerations and practical approach. Nat Protoc. 2009; 4:309-24.

39. Senavirathna LK, Fernando R, Maples D, Zheng Y, Polf JC, Ranjan A. Tumor Spheroids as an in vitro model for determining the therapeutic response to proton beam radiotherapy and thermally sensitive nanocarriers. Theranostics. 2013; 3:687-91. 